\title{
La formación inicial docente en educación inclusiva: experiencias y percepciones del futuro profesorado
}

\author{
Leopoldo Medina Sánchez - Universidad de Granada (D) 0000-0002-0643-2491
}

Recepción: 23.03.2020 | Aceptado: 02.02.2021

Correspondencia a través de ORCID: Leopoldo Medina Sánchez

iD 0000-0002-0643-2491

Citar: Medina Sánchez, L. (2021). La formación inicial docente en educación inclusiva: experiencias y percepciones del futuro profesorado. REIDOCREA, 10(3), 1-24.

\begin{abstract}
Resumen: La formación inicial de las futuras maestras y maestros para atender a la diversidad es la base para el desarrollo de actitudes y prácticas inclusivas que contribuyan tanto a la construcción de entornos de aprendizaje seguros y accesibles como a la creación de sociedades más justas. Por esta razón, el presente estudio tiene como objetivo conocer en profundidad las experiencias y percepciones de docentes en formación inicial respecto a la formación recibida en materia de educación inclusiva durante los tres primeros cursos correspondientes al módulo genérico del Grado en Educación Primaria (EP) de la Facultad de Ciencias de la Educación de la Universidad de Granada. Para ello, hemos utilizado un cuestionario por escrito estructurado y exploratorio, además de un análisis del plan de estudios del Grado en EP. Los principales resultados revelan que los participantes no se consideran lo suficientemente preparados para atender a la diversidad sobre todo en lo que respecta a una formación práctica de calidad. Asimismo, los datos sugieren la necesidad de un replanteamiento de la configuración del período de prácticas, así como del diseño del plan de estudios, de manera que se incrementen tanto la calidad como la cantidad de los contenidos teóricos y prácticos en materia de educación inclusiva.
\end{abstract}

Palabra clave: Educación especial.

Pre-service teacher's training in inclusive education: future teachers' experiences and perceptions

Abstract: Pre-service teaching programs in attention to diversity are the basis for the development of inclusive attitudes and practices that contribute both to the construction of safe and inclusive learning environments, as well as to the creation of fairer societies. For this reason, the objective of this study is to gain an in-depth understanding of the experiences and perceptions of pre-service teachers regarding their training in inclusive education during the first three academic courses which correspond to the generic module of the Degree in Primary Education (PE) of the Faculty of Educational Sciences of the University of Granada. To carry out this research, we have used a structured and exploratory written questionnaire, in addition to an analysis of the syllabus of the Degree in PE. The main results reveal that the participants do not consider themselves sufficiently prepared to attend to diversity, especially when it comes to an adequate training. Likewise, the data collected suggest the need to rethink the configuration of the school practices, as well as the design of the syllabus, so as to increase both the quality and quantity of the theoretical and practical content regarding inclusive education.

Keyword: Special education.

\section{Introducción}

La formación inicial de las maestras y maestros durante el Grado de Educación Primaria orientada a que lleven a cabo acciones socioeducativas inclusivas continúa representando uno de los principales focos de discusión científica -y de preocupación, en el ámbito educativo en una escala nacional e internacional (Boer, Pijl y Minnaert., 2011, Brandes et al., 2012, Izuzquizu, Echeita y Simón, 2015). En este sentido, la mayoría de investigaciones sitúan la figura del docente como pilar fundamental de la escuela inclusiva (Azorín, 2017; Cardona y Paz, 2012; Crisol, 2019; Durán y Giné, 2011; González et al., 2016). Igualmente, según varias investigaciones es el propio profesorado el que percibe la formación en educación inclusiva como el eje central de sus procesos formativos y posterior desempeño profesional (Pegalajar y Colmenero, 2014; Sevilla, Martín y Jenaro, 2017). Por lo tanto, consideramos esencial describir lo que se entiende en la actualidad por educación inclusiva con el fin de sentar las bases teóricas y dilucidar la perspectiva presente a lo largo de nuestro estudio. Así pues, 
tomamos como referencia la definición de Medina (2017) quien concibe la educación inclusiva como:

"un proceso pedagógico y ético, orientado al logro de una estructura social justa, lo que supone ofrecer a todas las personas, sin distinción, un tratamiento educativo equitativo y adecuado a sus características personales de diversa índole, actuando conforme al derecho a la educación". (Medina, 2017: 112)

De manera que, siguiendo con lo recogido por Medina (2017), podemos identificar cuatro rasgos comunes presentes en diversas definiciones de educación inclusiva: a) es un proceso crítico de búsqueda y reflexión constante que tiene como objetivo mejorar la distintas formas en que se atiende a la diversidad y que implica un cambio profundo tanto de los sistemas educativos como de la cultura escolar; b) está orientado a la localización y supresión de barreras con el propósito de promover mejoras políticas y prácticas inclusivas; c) debe impulsar la asistencia, la participación y el rendimiento de todo el alumnado; y d) ha de otorgar una atención particular al alumnado en riesgo de exclusión social y desigualdad educativa.

Del planteamiento anterior se desprende el concepto de atención a la diversidad como valor y fundamento teórico-práctico contenido en la legislación educativa nacional y regional (LOMCE 8/2013) y que supone un paso hacia adelante con respecto a los conceptos de integración e inclusión. El modelo de atención a la diversidad es abordado, por tanto, desde un enfoque holístico e interactivo que se dirige a toda la comunidad educativa y no únicamente a un grupo de discentes, alejándose así del modelo biomédico centrado en el déficit que sigue vigente, a veces de forma velada, en muchas normativas, instituciones, contextos y praxis. A ello se une una de las principales necesidades que surgen en pro de la atención a la diversidad que es la de formar al profesorado en investigación e innovación con la finalidad de reorientar el funcionamiento homogeneizador de la escuela a la que acude, cada vez más, un alumnado heterogéneo (Vigo y Soriano, 2014). No obstante, como sostienen Durán y Giné (2011), resulta conveniente recordar que la atención a la diversidad bajo criterios de calidad y equidad no depende únicamente de la formación del profesorado, sino que precisa de voluntad política (reconfiguración de la formación inicial y permanente y mayor dotación de recursos humanos y técnicos) y de acuerdos sociales guiados por valores tales como la igualdad y la justicia. Para ello, es estrictamente necesario, además, que las voces del alumnado y de las familias sean escuchadas y tenidas en cuenta (Vélez et al., 2016).

Retomando la cuestión de la formación de las maestras y maestros de Educación Primaria, Álvarez y Buenestado (2015) argumentan que la puesta en marcha de una educación inclusiva de calidad en el ámbito socioeducativo "requiere una formación inicial y continua del profesorado basada en conocimientos, competencias, valores y actitudes, vinculándose todos estos elementos al principio de justicia social" (p.628). Más concretamente, la mayoría de expertas y expertos en atención a la diversidad concuerdan en que el período de formación inicial del profesorado constituye un crisol donde se funden la mayoría de creencias, actitudes, opiniones e ideas en torno a la educación que orientará las futuras acciones pedagógicas de los docentes (Sevilla, Martín y Jenaro, 2017). En este sentido, el planteamiento de Hopkins y Stern (1996) en lo que se refiere a cómo puede ser la actuación del profesorado para crear y sustentar escuelas inclusivas, ha servido de punto de referencia para trabajos posteriores en torno al diseño de planes de estudios. Desde su punto de vista, la acción pedagógica del profesorado en lo que se refiere a educación inclusiva debe caracterizarse por:

"compromiso (voluntad de ayudar a todos los alumnos), afecto (entusiasmo y cariño hacia los alumnos), conocimiento de la materia enseñada (hacerla accesible para todos), múltiples 
modelos de enseñanza (flexibilidad y habilidad para resolver lo imprevisto), reflexión sobre la práctica y trabajo en equipo que promueva el aprendizaje entre los colegas" (Hopkins y Stern, 1996, citados por Durán y Giné, 2011: 168).

Igualmente, el progreso en educación inclusiva tiene como base en palabras de Durán y Giné (2011) una toma de decisiones en lo que se refiere a:

"los cambios que requieren el diseño y desarrollo del currículum; la dotación y redistribución de los recursos humanos y materiales, con sistemas de apoyo y asesoramiento; la organización de los centros (tiempos y espacios para la colaboración del profesorado, en un marco flexible y autónomo que promueva la participación de la comunidad) y los procesos de enseñanza y aprendizaje (centrándolos no únicamente en la enseñanza, sino en el alumnado)". (Durán y Giné, 2011: 157).

Sin embargo, pese a los avances en los enfoques y diseños de planes de formación, como hemos podido observar a lo largo de varias investigaciones, la formación inicial de futuros profesionales de la educación inclusiva no termina de ser suficiente (Gallego y Rodríguez, 2012; González et al., 2016; Medina, 2017; Vélez et al., 2016, Verdugo y Rodríguez, 2012). En concreto, la investigación realizada por Vélez et al. (2016) consistente en una comparativa entre Ecuador y España de la gran mayoría de planes de estudios de universidades de titularidad pública y privada, ha puesto de manifiesto que el número de asignaturas encaminadas a tratar la educación inclusiva es insuficiente en los dos países, lo que afecta directamente a la consolidación de conocimientos de base, al desarrollo de competencias, al cambio de actitudes, a la adopción de métodos de enseñanza y, por ende, a las prácticas inclusivas del profesorado en formación inicial de ambos contextos. Además, este equipo de investigación (ibídem) pone de relieve que la educación inclusiva "no es un asunto que haya ganado peso en los planes de estudio [...] en algunos casos incluso ha perdido importancia [...] la formación del profesorado en educación inclusiva no ha sido ni mucho menos una prioridad para quienes han diseñado el currículo [...]" (p.89). Todo ello, pese a la ampliación de la formación inicial de futuras maestras y maestros de tres a cuatro cursos venida de la mano del plan Bolonia. Paralelamente, estas autoras y autores puntualizan que en la inmensa mayoría de planes de estudio se sigue perpetuando la visión dicotómica de profesorado "generalista" y profesorado "especialista", lo que, de acuerdo con varias investigaciones (Echeita, 2012, Gallego y Rodríguez, 2012; Marchesi, 2001), tiene un efecto negativo sobre la confianza del profesorado generalista, puesto que no se siente lo suficientemente preparado para ofrecer una respuesta socioeducativa adecuada a las necesidades del alumnado con NEE. Además, este hecho obstaculiza la colaboración y cooperación entre el profesorado generalista y de educación especial en lo que concierne a la planificación de procesos de enseñanza y aprendizaje (León, 2011).

Como consecuencia de dicha visión dicotómica reflejada en numerosos planes de estudios, algunas investigaciones como la de Sapon y Shevin (2013) y González et al., (2016) han puesto de manifiesto que el profesorado relaciona mayormente la atención a la diversidad con atender al alumnado con NEE, sin llegar a hacer uso de un enfoque inclusivo, dirigido a todos sus discentes, independientemente de sus capacidades de trabajo, historia escolar, intereses y ritmos de aprendizaje. Esto representa una dificultad difícil de sortear para los futuros docentes que advierten cómo dicha visión dicotómica sigue enraizada no sólo en el plan de estudios sino en la cultura escolar de numerosas escuelas e instituciones de formación, lo que les genera dudas en torno a la definición y comprensión de las NEE y la forma de hacer frente a las barreras que impiden el aprendizaje y participación de todo su alumnado (Vigo, Soriano y Julve, 2010; Sevilla, Martín y Jenaro, 2017). 
Con el fin de paliar algunas de las carencias de los planes de estudios en materia de educación inclusiva, algunas autoras y autores han propuesto medidas para superar la mencionada visión dicotómica: incorporación de la educación inclusiva como contenido transversal en el currículum formativo y puesta en marcha de programas de formación especializada en posgrado (León, 2011); presencia de un número mayor de asignaturas dentro del currículum destinadas a la enseñanza y aprendizaje de fundamentos teóricos y prácticos en lo que se refiere a la atención a la diversidad, junto con la inclusión de modificaciones en los programas de prácticas que fomenten una relación mayor entre la teoría y la práctica a través de la reflexión guiada, la colaboración y la investigaciónacción (Barbosa-Vioto y Vitaliano, 2013); formación crítica y creativa orientada al desarrollo de actitudes positivas hacia la educación inclusiva (Sapon y Shevin, 2013; Vigo y Soriano, 2014); y una mayor experiencia de los formadores de formadores en contextos y procesos de educación inclusiva en distintas etapas educativas, de forma que puedan suponer un ejemplo de buenas prácticas para su alumnado (Vélez et al., 2016).

No obstante, los esfuerzos depositados por el gobierno nacional y regional en educación no han trascendido la tinta y España ha sido sancionada por la ONU en 2019 por no cumplir con la Convención de derechos de personas con discapacidad, tras haber discriminado y segregado a alumnas y alumnos principalmente en razón de los recortes en educación, según han reportado varias organizaciones como DOWN España y Plena Inclusión. Todo ello nos invita a reflexionar sobre el alcance de los recortes y su posible efecto negativo sobre las instituciones de formadores de futuros profesionales de la educación. Respecto a esto último, los resultados del estudio de Hunter-Johnson, Newton y Cambridge-Johnson (2014) demuestran que la falta de formación en educación inclusiva junto con la escasez de recursos, constituyen dos de los factores de mayor influencia en las percepciones de los docentes en formación inicial, muchas y muchos de los cuales ya han experimentado igualmente el impacto negativo de los recortes en educación en su formación durante las etapas obligatorias. Asimismo, pese a que en España existan estudios que sostienen que las actitudes de los futuros docentes hacia la atención a la diversidad son positivas en términos generales (Álvarez y Buenestado, 2014; Izuzquiza, Echeita y Simón, 2015; Tárraga, Grau y Peirat, 2013), siempre teniendo en cuenta el factor de deseabilidad social que puede actuar de sesgo en los resultados de determinadas investigaciones, son numerosos los autores y autoras que sostienen que dicha positividad se diluye en la práctica (Batsiou et al., 2008; Bravo, 2013; Izuzquiza, Echeita y Simón, 2015; Lindsay, 2010; Pegalajar y Colmenero, 2014; Sevilla, Martín y Jenaro, 2017). Entre las principales dificultades que impiden la puesta en marcha de prácticas inclusivas destacan, según González et al. (2016): "dificultades de índole organizativo y pedagógico como la escasez de recursos y de tiempo, el escaso apoyo de la administración educativa y de las familias, o la falta de formación específica. (p. 19).

Como hemos podido comprobar, la formación inicial para atender a la diversidad es vital para el desarrollo de actitudes y prácticas inclusivas. Por otra parte, numerosos estudios han puesto de relieve el impacto de las experiencias en atención a la diversidad de los docentes tanto en la frecuencia como en calidad sobre las actitudes y prácticas de los futuros maestros y maestras a corto y largo plazo (Álvarez y Buenestado, 2015; Tárraga, Grau y Peirat; Vigo y Soriano, 2014). Con respecto a dicho impacto, la literatura científica ha demostrado que las experiencias previas con alumnado con NEE en el Prácticum o bien en el ámbito familiar (Polo, Fernández y Díaz, 2011) tienen un efecto positivo sobre el desarrollo de actitudes positivas en el futuro profesorado (Boer, Pijl y Minnaert , 2011). A ello también contribuye el hecho de haber realizado prácticas educativas en centros escolares inclusivos mientras este recibía una enseñanza formal. De manera que. por lo general, cuanta más formación y experiencia, ya sea a través de cursar una especialización o mención e incluso una formación específica durante un posgrado, más 
positiva será la actitud y más adecuada será la respuesta socioeducativa a la diversidad (Álvarez y Buenestado, 2015; Granada et al., 2013). En este sentido, Arnett (2010) sostiene que los docentes mejor formados en educación inclusiva son aquellos que aplican en sus aulas un número mayor de estrategias metodológicas para atender a las distintas necesidades de su alumnado.

Contrariamente, existen voces críticas con las experiencias vividas por las maestras y maestros durante su formación inicial llegando incluso a poner sobre la palestra la calidad de los planes de estudios y de la enseñanza universitaria. Así pues, en el estudio de Pegalajar y Colmenero (2014) en el que se analizan las actitudes y percepciones de 428 docentes de centros de Educación Especial de Andalucía se hallaron:

"diferencias estadísticamente significativas en las actitudes y percepciones de los docentes según éstos hayan desarrollado o no actividades de formación práctica vinculada al ámbito de la educación inclusiva durante su período de formación inicial, siendo más favorables en el caso de aquellos que no disponen de tal formación." (p. 196).

En relación con lo anterior, Sevilla, Martín y Jenaro (2017) afirman que existe "un área de mejora en el diseño de los esquemas de prácticas" (p. 108). Esto se debe a que muchas de las acciones pedagógicas que realizan durante el Prácticum no han sido previamente planificadas por la institución formadora en cuestión, sino que estas a menudo responden a oportunidades de inserción laboral de los docentes o a cuestiones casuales. Por lo que resulta esencial que se alternen los contenidos teóricos con el trabajo de campo durante el período de realización de prácticas (Swain et al., 2012), además de ofrecerles experiencias que transformen los valores y creencias en cuanto a la enseñanza y el aprendizaje que traen a la universidad (Vélez et al., 2016; Vigo y Soriano, 2014).

Llegados a este punto, no cabe duda de que los planes de estudios y la experiencia determinan en gran medida las actitudes y las prácticas en línea con los principios y objetivos de la educación inclusiva, por lo que consideramos imprescindible conocer con mayor detalle las percepciones del alumnado universitario en cuanto a su formación. Por consiguiente, podemos destacar el estudio realizado por Izuzquiza, Echeita y Simón (2015) que arroja luz sobre las fortalezas y debilidades percibidas en cuanto a su formación de 86 recién egresados de los Grados de Maestro en Educación Infantil y Educación Primaria en la Universidad Autónoma de Madrid. Los resultados fueron obtenidos a partir de un cuestionario elaborado ad hoc tomando como base las dimensiones contempladas en el Perfil de Competencias del Profesorado Inclusivo procedentes del proyecto "Formación del Profesorado para la Inclusión" desarrollado en 2012 en el seno de la Agencia Europea para el Desarrollo de las Necesidades Educativas Especiales y la Educación Inclusiva. De forma que, en lo que respecta a las fortalezas percibidas por los egresados en lo que se refiere a la formación inicial recibida, los resultados del estudio fueron los siguientes: valorar en positivo la diversidad del alumnado; preocuparse por la aceptación del alumnado con capacidades diferentes por parte el resto de compañeros y compañeras; desarrollar una gran empatía hacia las distintas necesidades de sus discentes; ser consciente de la importancia de la autoestima, el bienestar emocional y las relaciones sociales en relación con la mejora del aprendizaje de sus futuros alumnos y alumnas; asumir la importancia de la escucha y tener en cuenta la opinión del alumnado y de sus familias; considerar la docencia como un proceso de formación continuo.

En lo que concierne a las debilidades, Izuzquiza, Echeita y Simón (2015) recogen las siguientes: preparación para atender a la diversidad (a todo el alumnado, con y sin NEE); preocupación por la dificultad que representa ofrecer una respuesta socioeducativa adecuada a todo el alumnado y por no poseer los conocimientos y habilidades 
necesarias para la enseñanza a un alumnado diverso; capacidad para fomentar la participación, la colaboración y la comunicación para con las familias en el centro escolar; conocimiento sobre métodos de investigación para una mejor comprensión de la realidad educativa y poder llevar a cabo mejoras significativas en su manera de enseñar.

Por último, una vez esbozados los antecedentes teóricos de nuestro estudio, queremos subrayar el predominio del uso de instrumentos de carácter cuantitativo en la literatura científica estudiada (cuestionarios en su mayoría) para abordar el tema que nos compete. Por esta razón, consideramos esencial disponer de un número mayor de datos desde un punto de vista cualitativo que profundicen en las percepciones de los futuros maestros y maestros de educación primaria en cuanto a su formación y experiencia con el fin de ampliar y contrastar la información extraída de manera cuantitativa.

\section{Objetivo}

El objetivo que ha orientado el desarrollo conceptual y el diseño metodológico del presente estudio ha sido conocer en profundidad las experiencias y percepciones de docentes en formación inicial respecto a la formación recibida en materia de educación inclusiva durante los tres primeros cursos correspondientes al módulo genérico del Grado en Educación Primaria de la Facultad de Ciencias de la Educación de la Universidad de Granada.

\section{Métodos}

\section{Participantes}

Las personas que han participado en este estudio están cursando el Grado en Educación Primaria y han optado por especializarse en la Mención en Educación Especial, en concreto, se encuentran en el inicio del primer semestre del cuarto y último curso, curso académico 2019/2020, en el momento en que tiene lugar la investigación que es en la primera semana de septiembre. El número total de participantes es de 38 , 36 mujeres y 2 hombres, con una edad comprendida entre los 22 y 24 años. La totalidad de los participantes han superado ya los créditos pertenecientes al módulo genérico (aquel que se dirige a todo el alumnado que cursa el Grado en Educación Primaria) durante los tres cursos anteriores, incluido el Prácticum I que consta de 20 créditos ECTS, es decir, comprende un total de 200 horas de prácticas externas. Con el fin de simplificar la forma de referirnos a las personas participantes y preservar su anonimato, a lo largo de este estudio utilizaremos la letra "P" junto con el número ordinal asignado para referirnos a las mismas. Por ejemplo:

P4: "No considero que mi formación me permita ofrecer una respuesta educativa adecuada. Echo en falta la práctica con dichos alumnos".

\section{Instrumentos}

En primer lugar, el instrumento que hemos desarrollado y en el que se fundamenta principalmente nuestro estudio es un cuestionario por escrito estructurado y exploratorio que combina preguntas de respuesta abierta con otras de carácter más cerrado (para conocer las preguntas incluidas en el mismo, consúltese el anexo I). El cuestionario está encaminado a describir con mayor profundidad las siguientes categorías temáticas:

a) El conocimiento de las personas participantes en lo que respecta a la educación inclusiva (enfoques y estrategias metodológicas para atender a la diversidad); 
b) sus percepciones en torno a sus experiencias previas (tanto en el Prácticum como aquellas procedentes de su vida personal como recuerdos de su trayectoria escolar y/o familiar, además de aquellas vividas en procesos de formación no formal);

c) sus percepciones en cuanto a la formación inicial recibida a lo largo de los tres cursos correspondientes al módulo genérico del grado en Educación Primaria;

d) percepciones en cuanto a las aptitudes y actitudes desarrolladas en relación con la educación inclusiva (fortalezas y debilidades).

El motivo por el que preferimos la modalidad escrita fue garantizar una argumentación mejor reflexionada y con mayor contenido que sustentara la objetividad de los datos tanto en lo que se refiere a ejemplos como en la terminología utilizada y sentimientos y emociones expresados de forma narrativa.

Las preguntas que lo conforman, tras haber sido evaluadas y matizadas por tres jueces externos a la Universidad de Granada, se construyeron, por un lado, conforme a lo que recoge la literatura científica en cuanto a la formación inicial de los futuros profesionales de la educación para ofrecer una respuesta socioeducativa a la diversidad de necesidades del alumnado siguiendo criterios de calidad y equidad y, por otro, en relación a los conocimientos y habilidades que para entonces deberían haber adquirido dichos participantes a lo largo de las asignaturas relacionadas con la atención a la diversidad contenidas en el plan de estudios.

Por esta razón (plantear y perfilar las preguntas del cuestionario) y no únicamente con el objetivo de triangular los datos en el análisis de los resultados, recurrimos, en segundo lugar, a un análisis documental centrado en las guías docentes de todas las asignaturas de carácter troncal y optativo para comprobar de cuántas asignaturas relacionadas estrechamente con la educación inclusiva se compone el plan de estudios en su totalidad (incluyendo las Menciones del cuarto curso) y si existen otras asignaturas en las que se aborde dicho tema de manera teórica y/o práctica e incluso de forma transversal.

Finalmente, con posterioridad a la compleción del cuestionario, hemos llevado a cabo conversaciones informales con los participantes para confirmar y/o matizar algunos de los datos obtenidos.

\section{Procedimiento}

A lo largo del segundo semestre del año 2019 se elaboraron y validaron las preguntas del cuestionario. El objetivo fue diseñar un cuestionario exploratorio que nos ofreciera una primera visión acerca de las percepciones que tenía el alumnado en formación inicial acerca de la formación recibida a lo largo de los tres cursos del módulo genérico y qué relación se establecía con sus experiencias previas (personales, profesionales y académicas).

El acceso a los participantes tuvo lugar al inicio de la asignatura Educación lingüística para el alumnado con NEE de la Mención en Educación Especial. Como docente de uno de los tres grupos de dicha asignatura, mi intención era conocer en profundidad cuál había sido su formación hasta el momento en educación inclusiva con el objetivo de desarrollar contenidos de refuerzo, de ampliación y/o complementarios a partir de las fortalezas y/o carencias formativas y actitudinales que presentara mi alumnado al inicio de curso, partiendo igualmente de sus intereses. Por este motivo, el día de la presentación de la asignatura (inicio del primer semestre del curso 2019/2020), tras presentarles de manera general los objetivos, contenidos, metodología y evaluación de 
la misma, se les pasó el cuestionario por escrito con la finalidad de que, además, sirviera de evaluación inicial.

Para ello, se les ofreció una serie de instrucciones: "el cuestionario es anónimo; disponéis de una hora y media para responder por escrito y en el orden que prefiráis; intentad ejemplificar cada uno de vuestros argumentos de manera narrativa tratando de describir los sentimientos $\mathrm{y} / \mathrm{o}$ emociones que os provocaron determinados acontecimientos; evitad hablar con vuestros compañeros y compañeras durante su compleción, así como el uso del móvil".

La razón por la que decidimos pasar el cuestionario justo en el comienzo de curso fue la de analizar una primera entrada datos con la intención de ampliar y contrastar dichos datos a lo largo de estudios posteriores con los mismos participantes (a través de entrevistas en profundidad, observación participante y análisis documental de los trabajos que realizaran). Del mismo modo, el objetivo de salvaguardar la identidad de las personas participantes obedeció al deseo de crear un ambiente de seguridad, propicio a que se expresaran con total libertad, hecho que, desde nuestro punto de vista, se vio favorecido por el uso de la escritura como medio de expresión y reflexión, en concreto, de la narración como pudimos comprobar durante el análisis de los datos.

\section{Análisis de datos}

El procedimiento de investigación que hemos llevado a cabo es más propio de la metodología cualitativa, dada la naturaleza abierta de las preguntas planteadas en el cuestionario y el proceso seguido para el análisis de datos, y su dimensión epistemológica se corresponde con el paradigma interpretativo.

De manera que, para cumplir con el objetivo de nuestro estudio, hemos realizado un análisis de los datos basándonos en las orientaciones metodológicas de Bisquerra et al. (2019) y Karsenti y Savoie-Zajc (2018). De modo que, los datos extraídos han sido analizados a través de un proceso de codificación de categorías temáticas que ha constado fundamentalmente de cuatro etapas: 1) transcripción y organización de los datos en una matriz en formato de Excel; 2) realización de tres lecturas profundas con períodos de pausa de 10 días (Miles, Huberman y Saldaña, 2014) que nos ha facilitado una primera codificación temática siguiendo una lógica inductiva; 3) realización de una lectura selectiva con el fin de reducir los datos siguiendo una lógica deductiva y; 4) verificación e interpretación de los datos.

\section{Resultados}

En las líneas que siguen expondremos los resultados más relevantes de nuestro estudio ilustrando las experiencias y percepciones de las personas participantes con la finalidad de cumplir con el objetivo de investigación.

Para facilitar su comprensión hemos estructurado los datos obtenidos en torno a las siguientes categorías temáticas:

\section{1) Conocimiento en cuanto a la educación inclusiva}

\section{1) El enfoque}

En lo que concierne al enfoque desde el que conciben la atención a la diversidad, la mayoría de los participantes, 24 (63\%), describe un enfoque basado en los principios y objetivos en línea con la educación inclusiva: 
P6: "tratar de brindar las mismas oportunidades a cada persona teniendo en cuenta sus capacidades, habilidades y necesidades...satisfaciéndolas para conseguir su bienestar físico, psicológico y social".

No obstante, hemos hallado que 8 de los 38 (21\%) de los participantes aún mantiene un enfoque basado en el modelo biomédico del déficit, es decir, orientado a atender únicamente las dificultades y/o necesidades de un grupo de alumnas y alumnos:

P9: "es una manera de atender al alumnado con dificultades de aprendizaje".

P28: "la atención a la diversidad se refiere a la adaptación que algún alumno necesite en su currículum para un mejor desarrollo académico y personal".

El resto de participantes, 6 de los 38 (16\%), no termina de describir claramente su enfoque quedándose a medio camino entre el enfoque basado en una educación inclusiva y el modelo del déficit:

P4: "es la ayuda que se presta a todo el alumnado que presenta problemas con un idioma por ser extranjero hasta el alumnado que necesita ayuda para moverse por el aula por encontrarse en silla de ruedas".

\section{2) Concepto de Necesidades Educativas Especiales (NEE)}

Como hemos podido comprobar, la mitad de los participantes, $19(50 \%)$, no ha sabido explicar con precisión, ni siquiera de manera general, el concepto de Necesidades Educativas Especiales, confundiéndolo generalmente con el concepto de ACNEAE (alumnado con necesidades específicas de apoyo educativo) o con otras categorías de alumnado que se incluyen dentro de la categoría ACNEAE como el alumnado con altas capacidades:

P7: "es todo aquel alumnado que presente ciertas características que hagan necesarias una 0 varias adaptaciones curriculares, ya sean significativas o no, durante una o varias asignaturas. Es importante señalar que todo el alumnado con NEAE se considera ACNEE, pero no todo ACNEE posee ACNEAE".

Asimismo, 11 de los participantes (30\%), han ofrecido una definición en la que eluden las categorías que abarca este término o se limitan a afirmar que es el alumnado que presenta dificultades de aprendizaje sin precisar cuáles ni el origen, por lo sigue siendo una definición demasiado general.

En contraposición, 8 de 38 participantes (20\%) sí que han realizado una definición más precisa, asociando este tipo de necesidades a discapacidad o trastornos graves de la conducta, de la personalidad o del desarrollo:

P36: "es aquel que presenta alguna necesidad educativa especial, es decir, algún tipo de discapacidad física o psíquica, que le impide seguir el ritmo de clase".

\section{3) Enfoques y estrategias metodológicas para atender a la diversidad}

\subsection{1) Enfoques y/o metodologías para atender a la diversidad}

Como hemos podido observar, no todos los participantes han ofrecido ejemplos de enfoques o metodologías, es decir, la información proporcionada respecto a este ámbito es nula en 26 de los 38 participantes. De la misma forma, entre los participantes que sí han facilitado información, algunos no han ofrecido más de un ejemplo de enfoque 0 
metodología. No obstante, debemos destacar que la mayoría de respuestas representan ejemplos de enfoques y metodologías adecuadas para atender a la diversidad según la literatura científica y que, a pesar de que el conocimiento a nivel individual es en general escaso, al analizar las respuestas de los participantes que sí han respondido a esa pregunta podemos verificar que el nivel de conocimiento sobre educación inclusiva como grupo es elevado.

En lo que respecta a enfoques o metodologías para atender a la diversidad, los participantes han indicado los siguientes: metodologías que facilitan la motivación (P2; P32); aprendizaje por descubrimiento/experimental (P2); aprendizaje centrado en el alumno o alumna (P2; P11; P18); pedagogía diferenciada (P3); metodología flexible y ecléctica (P5; P22; P32); metodologías activas como el Aprendizaje Basado en Proyectos (ABP) (P6; P7; P38); aprendizaje cooperativo (P7); enfoques visuales, manipulativos y prácticos (P8); metodología integradora (P24); metodología inclusiva (P27); metodologías basadas en enfoques constructivistas (P38).

\subsection{2) Estrategias para atender a la diversidad}

Según los datos recabados, sí ha habido un número mayor de participantes que han ofrecido información en relación con estrategias metodológicas dirigidas a la atención de la diversidad, en concreto, 25 de los 38 participantes. Por consiguiente y a diferencia de lo ocurrido con la información proporcionada sobre enfoques y metodologías, es muy probable que los participantes desconocieran el nombre específico de determinados enfoques o metodologías y decidieran recogerlos como estrategias describiéndolos 0 parafraseándolos con sus palabras de manera general. En este sentido, como podemos observar, la personalización de la enseñanza y el trabajo en grupo han sido destacadas como estrategias para atender a la diversidad por un número mayor de participantes.

En lo que se refiere a estrategias para atender a la diversidad, los participantes han señalado: personalización de la enseñanza (P1; P3; P5; P6; P7: P10; P11; P12; P18; P32); trabajo en grupo (P8; P15; P21; P25; P26; P28; P34); aprendizaje colaborativo (P21; P38); uso de canales visuales (P2; P34); realización de adaptaciones curriculares significativas o no significativas (P19; P25); utilización de las TIC (P15; P25); uso de un lenguaje inclusivo (P27; P35); tener en cuenta las necesidades, intereses y dificultades (P3); lecturas adaptadas (P3); fichas de refuerzo (P3); evaluación inicial (P6); coordinación estrecha alumno-profesor-familias (P6); adaptación del temario (P33); aprendizaje autónomo (P21); gamificación (P34); escribir en Braille (P30); utilizar mapas conceptuales (P33); uso de música (P34); uso de la pintura (P34); realización de lecturas sobre la diversidad (P35); que el alumnado aprenda Lengua de Signos (P36).

\subsection{4) Actividades para atender a la diversidad}

Los datos recogidos sugieren que, pese a que las actividades indicadas puedan ser adecuadas para atender a la diversidad, la mayoría de participantes desconocen ejemplos prácticos de actividades, ya que sólo 4 de 38 han ofrecido ejemplos de actividades, siendo algunos de ellos demasiado generales.

En cuanto a las actividades, lo participantes recogen las siguientes: pequeños debates en grupo (P4); exposiciones orales por grupos (P4; P32); realizar obras de teatro inventadas (P4); actividades lúdicas (P8); actividades orales y escritas en gran grupo (P20); actividades de refuerzo (P20); actividades atractivas y dinámicas como teatros (P32); narraciones de cuentos (P32); actividades que impliquen la psicomotricidad (P32). 


\subsection{5) Recursos para atender a la diversidad}

Como podemos observar, muy pocos participantes, 4 de 38, han dado ejemplos de recursos humanos (especialistas) y técnicos (TIC). Consideramos que la información recabada a nivel de grupo respecto a los recursos es escasa y muy general.

Los participantes han señalado como recursos: uso de las TIC (P15; P25); apoyo de especialistas (P6); intérprete de Lenguas de Signos (P36).

\section{4) Uso de términos inclusivos y su relación con las actitudes}

En general, la mayoría de los participantes (74\%) han utilizado términos y fórmulas inclusivas -aunque poco precisas en cuanto al uso de términos específicos para hacer referencia a enfoques y metodologías para atender a la diversidad como mencionamos anteriormente-. Por ejemplo: "alumnado con NEE", "alumnado con dificultades de aprendizaje", "alumnado con discapacidad", "alumnado con autismo", "alumnado con capacidades diversas" ... Sin embargo, a lo largo del discurso de algunos participantes se ha hecho uso de términos que revelan, por una parte, el desconocimiento o la no consolidación del conocimiento en materia de atención a la diversidad poniendo de manifiesto carencias en su formación inicial, ya sea durante las asignaturas destinadas a la formación en educación inclusiva o durante el período de prácticas. En este sentido, nos ha llamado especialmente la atención el uso de los términos "retraso mental" y "retraso madurativo" por parte de 5 participantes (13\%), independientemente del enfoque sobre atención a la diversidad declarado previamente (dos de ellos describieron un enfoque inclusivo, otros dos, un enfoque general y uno, un enfoque centrado en el déficit).

Por otra parte, otros 5 participantes (13\%) han hecho uso de términos o fórmulas que, tomando como referencia el contexto en que han sido enunciadas, revelan una cierta toma de distancia y falta de empatía con respecto a la diversidad del alumnado al que los participantes describen como: "aquellos alumnos...", "este tipo de alumnado", "alumnos de este tipo", "alumnos extranjeros", "esos alumnos", "hacer frente a la diversidad", "enfrentarse a alumnos diversos", "integrar a un alumno" e "integración de los alumnos que...".

\section{2) Percepciones sobre experiencias previas}

Las personas participantes han descrito sus experiencias previas basándose principalmente en el Prácticum I realizado durante el curso 2018-2019. Los datos recogidos a partir de esta pregunta giran en torno a la adecuación de las adaptaciones metodológicas observadas durante este período, la idoneidad de la realización o no de las mismas y el tipo de adaptaciones o estrategias llevadas a cabo. En este sentido, todos los participantes otorgaron una especial importancia a la implementación de adaptaciones y estrategias metodológicas con el fin de personalizar en la medida de lo posible los procesos de enseñanza y aprendizaje. Sin embargo, se mostraron contrarios a la no realización de adaptaciones y a la elaboración de determinados tipos de adaptación percibidos como negativos para el aprendizaje de todo el alumnado con NEE como el uso predominante del libro de texto y el recurso a libros de lectura "demasiado" adaptados o por debajo de la capacidad de trabajo real del alumno o alumna y de sus intereses, entre otros.

\section{1) Experiencias adecuadas}


El primer dato que despunta es que 10 participantes de 38 (26\%) afirmaron no haber observado ninguna experiencia en que se atendiera a la diversidad de forma adecuada durante el Prácticum $I$, ni siquiera tener recuerdos de otras experiencias personales o profesionales. A ello se une el hecho de que otra decena de participantes (26\%) apenas aportan datos de ejemplos de atención a la diversidad apropiados, siendo mucho más amplia la información proporcionada por los mismos en lo que se refiere a la observación de experiencias percibidas como inadecuadas. Dicho de otro modo, 10 participantes no han ofrecido ejemplo alguno de experiencias adecuadas y otros 10 proporcionan una información muy escasa, lo que suma un total de 20 participantes de 38 (52\%) que declaran apenas haber tenido ejemplos de experiencias adecuadas fundamentalmente durante su período de prácticas perteneciente al módulo genérico de formación inicial.

Los participantes que ofrecieron una información mayor respecto a experiencias adecuadas de atención a la diversidad, 18 de 38 (48\%) las identifican como aquellas situaciones en las que el profesorado del centro escolar donde realizaron las prácticas llevaba a cabo una serie de adaptaciones y estrategias metodológicas con el alumnado, considerando más inclusivas y convenientes aquellas en las que estas medidas representaban una acción pedagógica dirigida a todo el grupo-clase y no solo a uno o varios grupos de alumnos y alumnas:

P5: "en el Prácticum de tercero se atendía a la diversidad dando a cada uno la evaluación y ritmo que necesitara, así como la figura de un profesor de apoyo. La profesora no seguía como tal únicamente y principalmente el libro de texto, sino que ella misma realizaba actividades o fichas para el aprendizaje y ritmo que cada uno necesitara".

P11: "durante el Prácticum la docente se percató de que había varios niveles de lectura en el aula por lo que a cada alumno le proporcionó la lectura más adecuada. Mientras un grupo leía cuentos breves, otros leían cuentos más extensos y de mayor vocabulario. Esta medida fue adecuada porque ningún alumno se quedaba estancado y todos continuaban con su aprendizaje".

De la misma manera, dichos participantes perciben como apropiadas las siguientes adaptaciones y estrategias metodológicas: personalización de la enseñanza; uso de las TIC; uso de las TIC como herramienta para personalizar la enseñanza; aprendizaje cooperativo y creación de grupos heterogéneos para favorecer la inclusión social; uso de juegos; utilización de sistemas de recompensa como la economía de fichas para promover la motivación y la participación; uso de técnicas de comprensión lectora y de escritura; dar más tiempo para la realización de tareas; adaptación de exámenes dándole más tiempo al alumnado que así lo necesite, así como simplificando los enunciados; ofrecer un mayor apoyo visual al alumnado con dificultades para aprender; respetar el ritmo y el tiempo de cada alumno para resolver las tareas y/o participar en una actividad; ubicación estratégica del alumnado que así lo requiera; aumento de la talla de los textos; uso de repeticiones corales para la expresión oral; promoción de valores y actitudes tales como el respeto, la tolerancia y la empatía; uso de materiales o actividades de refuerzo; presencia de un profesional de apoyo dentro del aula ordinaria; apoyo de otros profesionales de la educación como logopedas y profesionales de Lengua de Signos.

\section{2.) Experiencias no adecuadas}

A pesar de que el número de respuestas sea mayor en lo que se refiere a experiencias percibidas como inadecuadas para la atención a la diversidad, los datos indican que una gran mayoría de los participantes comparten percepciones muy similares en cuanto a determinadas experiencias vividas: desatención del alumnado con NEE en aula ordinaria; atención de las necesidades socioeducativas del alumnado con NEE 
principalmente en el aula de PT (Pedagogía Terapéutica) o AL (Audición y Lenguaje); no realización de adaptaciones ni a nivel pedagógico ni social; no realización de adaptaciones del material curricular; adaptaciones del material curricular poco adecuadas; adaptaciones incongruentes por basarse en una expectativa muy baja respecto al aprendizaje y rendimiento del alumno o alumna; actitudes negativas por parte del profesorado hacia el alumnado con NEAE, especialmente hacia el alumnado con NEE, como impaciencia, gritos, ridiculización, intolerancia y burlas; insuficiencia de recursos humanos y materiales en la clase ordinaria; carencias en el seguimiento y en la evaluación del alumnado por parte del profesorado.

A continuación, recogemos algunos de los ejemplos de experiencias inadecuadas que mejor recogen la convergencia de perspectivas de los participantes (para consultar las descripciones realizadas por el resto de participantes, consúltese la tabla I en el anexo):

P3: "en las prácticas que realicé en tercero las adaptaciones que se daban a los alumnos con NEE se limitaban a un refuerzo fuera del aula, con lecturas adaptadas y libros de un nivel más bajo respecto a su edad. Dentro del aula se utilizaban libros "más fáciles", que no estaban adaptados y el uso de fichas de "refuerzo". Considero que el uso de materiales de un nivel menos no es una adaptación real ni ajustada a las necesidades y demandas de cada menor, considero que es una práctica inadecuada."

P5: "en el Prácticum estuve en la clase de $2^{\circ}$ de primaria, la profesora únicamente se guiaba por el libro y por lo que éste exigía, sin embargo, no todos los alumnos presentaban las mismas necesidades, ya que una alumna no escribía ni leía correctamente y no hacía por pararse ni apoyarla. Lo mismo ocurría con un alumno con altas capacidades que se quedaba parado todo el tiempo".

P6: "en mi centro de prácticas no se atendía a la diversidad, puesto que un alumno que presentaba dificultades no fue atendido adecuadamente, ya que se le desatendía en el aula ordinaria mientras el resto seguían el ritmo normal de la clase. Mientras, el alumno con necesidades pasaba el tiempo realizando dibujos en el cuaderno y durante toda la jornada escolar permanecía en la silla sin atención ni adaptación. Además, no se le entregaron los materiales escolares hasta pasados tres meses del inicio del curso".

P27: "en los centros que conozco no se lleva a cabo el proceso de la inclusión, es decir, a los alumnos que presentan alguna dificultad se les ha sacado de clase con el profesor/a de apoyo. Por ejemplo, en las prácticas de tercero había en el aula una alumna con déficit de audición y la sacaban prácticamente todo el día. A lo largo de mi vida todavía no he visto a ningún docente atendiendo adecuadamente a la diversidad. Sí que he los he visto interesándose por el alumno/a, intentando que sus capacidades mejoraran, pero no he visto una metodología inclusiva. He observado que algunos docentes a alumnado con NEE les han puesto en clase a hacer actividades distintas a las que están siguiendo el resto de compañeros sin ninguna supervisión del docente hacia ese alumnado".

\section{3) Percepciones sobre la formación inicial recibida}

Los datos correspondientes a las percepciones de las personas participantes en torno a su formación inicial a lo largo del módulo genérico, revelan los siguiente:

a) 24 de 38 participantes afirman que no se consideran preparados para ofrecer una respuesta socioeducativa bajo criterios de calidad y equidad al alumnado con NEE. De acuerdo con sus percepciones, los participantes apuntan a una escasez de formación teórica y práctica en este ámbito. Sus principales argumentos podemos distinguirlos, por 
un lado, en percepciones en cuanto al contenido teórico y, por otro lado, percepciones en cuanto al contenido práctico.

En lo que respecta al contenido teórico que se imparte en la facultad, los participantes consideran que es insuficiente y demasiado general y que apenas se aborda el contenido relacionado con el alumnado con NEE:

P29: "no estoy preparada para ofrecer respuestas de calidad a los alumnos de este tipo, es decir, hacia aquellos que presentan alguna diversidad o necesidad. No me han enseñado casi nada de estos temas en todo lo que llevo de carrera. Deberíamos de ver casos reales para saber cómo actuar ante ellos y pienso que en este año podré aprender muchas cosas, pero pienso que con solo un curso no podré aprender los millones de casos que presentan los alumnos".

P33: "no me veo preparada para ofrecer una respuesta socioeducativa de calidad, puesto que no tengo mucha formación, ya que en la carrera he tenido pocas asignaturas orientadas a la atención a la diversidad".

En lo que concierne al contenido práctico, los participantes afirman que apenas han realizado casos prácticos durante las clases y que en el Prácticum no han tenido la oportunidad de observar ni llevar a cabo ejemplos de buenas prácticas:

P11: "claramente, no. A día de hoy no conozco gran cantidad de recursos para dar respuestas a estos alumnos, así como la falta de información acerca de muchas NEE. Por otro lado, el diagnóstico tampoco se ha trabajado profundamente, por lo que me falta conocimiento para poder realizarlo con éxito".

P17: "no me siento preparada para atender correctamente a un alumno con NEE. Echo en falta más información y sobre todo recursos y técnicas para atender correctamente a este tipo de alumnado. Con lo que he aprendido en la carrera no sería capaz de ofrecer una respuesta socioeducativa adecuada, ya que he aprendido cosas teóricas en su mayoría, siendo lo más importante saber poner todo en práctica".

Además, uno de los participantes declara echar en falta haber realizado más prácticas guiadas sobre casos reales durante el período de prácticas externas:

P19: "considero que mi formación hasta ahora no me permite ofrecer una respuesta socioeducativa de calidad y equidad al alumnado ACNEE, pues considero que es insuficiente. Se echa en falta casos prácticos con alumnos reales donde el maestro esté pendiente de mi forma de proceder y me corrija los fallos y me provea de feedback".

No obstante, pese a que 24 de 38 personas participantes hayan declarado no sentirse lo suficientemente preparadas ni en la teoría ni en la práctica, 4 de ellas afirman que su actitud ha mejorado respecto a la toma de conciencia de que hay que atender socioeducativamente a todo el alumnado:

P12: "creo que todavía no estoy lo suficientemente capacitada para atender al alumnado con NEE. Durante la carrera no me han enseñado a hacerlo, pero sí he aprendido lo suficiente en el Prácticum a valorar el esfuerzo de cada individuo a pesar de tener alguna NEE. Echo en falta estar formada profundamente en este tema. No nos preparan para salir y atender y enseñar a niños con alguna necesidad".

P14: "mi formación me ha permitido darme cuenta de que se debe atender a la diversidad. Soy consciente de que todo el alumnado, tenga o no ACNEE, son iguales tanto en valor, libertad, oportunidades...pero sí que es cierto que aún no poseo los conocimientos necesarios para saber qué pautas debo de seguir para tratar a los alumnos con NEE. A veces dudo sobre qué palabras usar para referirme a ACNEE, ya que pueden resultar discriminatorias y pienso que debería ser algo que ya nos tendrían que haber enseñado y nosotros aprendido". 
b) De acuerdo con los datos extraídos de 12 de 38 personas participantes, estas se hallan a medio camino entre percibirse o no preparados para atender a las necesidades de todo su alumnado. Dicho de otro modo, consideran que existen aspectos importantes de su formación susceptibles de mejora como pueden ser la comunicación con las familias y la realización de adaptaciones curriculares. En este sentido, todos perciben que su formación ha sido mayor en un plano teórico con respecto al práctico:

P36: "mi formación es adecuada en algunas cosas y en otras no. No se nos prepara para hablar con las familias en situaciones complicadas, las prácticas son demasiado cortas y no te da lugar a conocer el sistema en sí. Echo en falta más formación práctica porque al fin y al cabo trabajamos con personas y ese es el trabajo más importante".

P38: "considero que mi formación es insuficiente para atender al alumnado con NEE. Damos demasiada teoría y poca práctica. Echo en falta más casos prácticos. Quizá sepa la teoría, pero de práctica poco. Me gustaría saber crear materiales útiles. También me gustaría saber hacer una adaptación curricular, ya que no nos han enseñado a hacerla".

c) Las 2 personas participantes restantes de 38 declaran sí considerarse lo suficientemente formadas para atender a todo a su alumnado, incluido al más vulnerable. No obstante, ambas coinciden en que dicha formación la han adquirido principalmente a través de experiencias laborales o voluntarias, siendo para una de ellas especialmente relevante el Prácticum y el hecho de ser tutora legal de una persona con discapacidad intelectual:

P3: "actualmente, sí, puesto que me he formado por mi cuenta y he tenido la suerte de poder trabajar con menores con NEE tanto de forma laboral como voluntaria. Si solo hubiera cursado magisterio de primaria, sí que necesitaría mucha más formación para ser futura docente".

P21: "resulta precipitado poder afirmarlo, pero sí he tenido experiencia y prácticas tanto en el Prácticum, Ciclo formativo y experiencia laboral como para defenderme con algunos colectivos y trabajar con ellos. Al haber hecho seis meses de prácticas en un centro específico para parálisis cerebral y en respiros familiares con TEA [trastorno del espectro autista] y PCE [parálisis cerebral], conozco cómo se trabaja y el día a día al haber sido también voluntaria en colonias 24 horas con una persona y en domicilios. En el Prácticum había varios alumnos NEAE y de los que pude aprender estrategias que la PT hacía con ellos y cómo se trabajaba y, en mi caso particular, ser tutora legal de una persona con un retraso mental leve. Me queda un recorrido largo aún, pero ya tengo varias experiencias y recorrido al menos".

\section{4) Percepciones en lo que respecta a actitud y aptitud}

\section{1) Fortalezas}

Los participantes han indicado fundamentalmente: empatía, vocación, paciencia, cariño, confianza, actitud positiva, capacidad de adaptación, constancia, perseverancia, compromiso y formación autodidacta y/o extracurricular:

P3: "mis fortalezas son paciencia, cariño, pasión, empatía, firmeza, alegría, capacidad de adaptación e imaginación para realizar las adaptaciones necesarias".

P12: "me siento una persona con vocación, me implico en mi trabajo dando lo mejor de mí misma transmitiendo confianza y ayuda".

P26: "he realizado varios cursos de formación relacionados con el tema que me puede ser útiles". 
Cabe señalar que 10 participantes de 38 no han ofrecido información alguna en referencia a sus fortalezas. Por el contrario, sí han proporcionado datos en torno a sus debilidades.

\section{2) Debilidades}

En lo que concierne a las debilidades, los participantes concuerdan mayormente en que son la falta de formación práctica y de experiencias en lo que respecta a la atención a la diversidad y, en concreto, al alumnado con NEE. Además, 10 de 38 afirman sentir miedo e inseguridad como consecuencia de no saber cómo atender a la diversidad de manera adecuada:

P4: "miedo e inseguridad al llegar a una clase y no saber cómo enfrentarme a la diversidad, para que todo el alumnado esté satisfecho".

P6: "[...] ese es el mayor miedo, no saber cómo enfrentarse para brindarle la mejor calidad de vida y educativa a nuestros alumnos".

P24: "considero muy difícil integrar a un alumno con el resto de sus compañeros, ya que las aulas están formadas por muchos alumnos y cada uno es diferente y tiene un ritmo de aprendizaje distinto, por lo que sería muy difícil estar con todos a la vez e integrarlos de manera adecuada. Uno de mis principales miedos es no lograr que alumnado con NEE avance tanto académicamente como personalmente".

\section{5) Análisis del plan de estudios en materia de educación inclusiva}

Tras haber llevado a cabo un análisis del plan de estudios del Grado en Educación Primaria de la Facultad de Ciencias de la Educación de la Universidad de Granada centrado en los cuatros cursos que lo conforman, el módulo genérico correspondiente a los tres primeros cursos y el módulo específico o mención correspondiente al último curso, hemos comprobado lo siguiente:

Por un lado, dentro del módulo genérico, son dos las asignaturas del segundo curso de carácter troncal cuyos contenidos teóricos y prácticos, así como los objetivos y competencias están estrechamente relacionados con la educación inclusiva. Paralelamente, son otras cinco asignaturas también de carácter troncal en las que se incluye un tema relacionado con la educación inclusiva (generalmente el temario de las asignaturas está compuesto de 7 a 9 temas) con sus consecuentes contenidos prácticos al igual que objetivos y competencias.

Por otro lado, dentro del módulo específico o mención, únicamente la "Mención en Educación Especial" se caracteriza por que la totalidad de los contenidos teóricos y prácticos, además de los objetivos y competencias, estén encaminados a formar a los futuras maestras y maestros para que puedan ofrecer una respuesta socioeducativa de calidad y equidad a un alumnado diverso. Entre las menciones restantes, únicamente hemos localizado tres menciones en las que se incluye un tema relacionado con la atención a la diversidad incluido dentro del temario de una de las asignaturas que las conforman, concretamente, en la "Mención en Educación Física" (en la asignatura de Didáctica de la Educación Física en Educación Primaria), en la "Mención en Lengua Extranjera: Inglés" (en la asignatura de Didáctica de la cultura de la lengua extranjera) y en la "Mención en Lengua Extranjera: Francés"(en la asignatura de Didáctica de la cultura de la lengua extranjera).

En resumidas cuentas, durante la formación general que han recibido los participantes a lo largo de los tres primeros cursos, son un total de dos asignaturas y cinco temas en 
los que se incluyen contenidos teórico-prácticos, así como objetivos y competencias en relación con la educación inclusiva. A lo largo de la especialización, se aborda de forma específica la educación inclusiva en la totalidad de las asignaturas que conforman una de las seis menciones, un total de cuatro asignaturas. En el resto de menciones la presencia de la educación inclusiva como contenido teórico-práctica es muy escasa o inexistente.

\section{Discusión}

En las líneas que siguen reflexionamos acerca de los aspectos más relevantes de nuestro estudio puestos de manifiesto por los datos ofrecidos por las personas participantes con el fin de compararlos con los resultados del análisis del plan de estudios y la literatura existente al respecto:

a) En relación con los datos relativos al conocimiento de los participantes, hemos hallado que, en cuanto al conocimiento teórico, algo más de la mitad de ellos describen un enfoque para atender a la diversidad basado en los principios y objetivos de la educación inclusiva, aunque el resto presenta dudas en cuanto a dicho enfoque e incluso algunos describen un enfoque basado en el modelo biomédico del déficit. Dichas dudas siguen presentes en lo que se refiere al concepto de Necesidades Educativas Especiales, concepto que sólo han sabido explicar 8 participantes de 38 con precisión atención a la diversidad. En lo que respecta al conocimiento práctico, 26 participantes no han proporcionado ningún tipo de información en lo que se refiere a ejemplos de enfoques o metodologías inclusivas. Entre los participantes que sí han facilitado dicha información, muy pocos han sabido ofrecer más de un ejemplo. Lo mismo ocurre con los datos proporcionados en torno a actividades y recursos para atender a la diversidad, es decir, son muy escasos. Contrariamente, ha sido mayor el número de participantes que han aportado información en lo que concierne a estrategias metodológicas dirigidas a la atención a la diversidad como la personalización de la enseñanza y el trabajo en grupo. Igualmente, la mayoría de los participantes ha hecho uso de términos y fórmulas inclusivas para dirigirse a la diversidad del alumnado. Sin embargo, son 10 los participantes que han utilizado términos o fórmulas menos inclusivas como "retraso mental" o "alumnos con retraso madurativo", "alumnos de este tipo", "alumnos extranjeros", "integración de los alumnos que", "enfrentarse a alumnos diversos". Debemos, pues, subrayar que el término "retraso mental o madurativo" ha caído en desuso por sus connotaciones peyorativas al menos desde 2005, tras el impacto de la Declaración de Salamanca y gracias a publicaciones como la de Palacios y Romanach (2008). Dicho término ya no se utiliza en manuales y otros documentos publicados a lo largo de la última década por la Organización Mundial de la Salud (OMS), la Asociación Americana de Psiquiatría (APA), la Asociación Americana de Discapacidades Intelectuales (AAIDD) y la Agencia Europea para las necesidades educativas especiales y la inclusión educativa. Tampoco aparece en documentos oficiales estatales ni regionales en materia de educación. Por lo que su utilización sugiere que o bien los participantes no han dispuesto de apuntes y referencias bibliográficas actualizadas o han sido influenciados por el uso de dicho término en los centros escolares durante las prácticas externas. Asimismo, el análisis del conocimiento de las personas participantes pone de manifiesto una mayor adquisición de conocimientos teóricos que de conocimientos prácticos. No obstante, los conocimientos teóricos no han sido asimilados por la mayoría de los participantes, puesto que presentan dudas terminológicas para referirse al alumnado, así como lagunas en torno al concepto de Necesidades Educativas Especiales y el enfoque a seguir para atender a la diversidad. Por lo tanto, consideramos, teniendo en cuenta la mayoría de perspectivas de los participantes en cuanto a su formación, los resultados del análisis del plan de estudios y los datos 
procedentes de la literatura científica, que la formación inicial en educación inclusiva de las y los futuros docentes es insuficiente, lo que influye de manera negativa sobre la consolidación de conocimientos de base, el desarrollo de competencias, el cambio de actitudes, la adopción de métodos de enseñanza y las prácticas inclusivas (Gallego y Rodríguez, 2012; González et al., 2016; Medina, 2017; Vélez et al., 2016; Verdugo y Rodríguez, 2012).

b) En cuanto a las percepciones sobre experiencias previas, la mayoría de los participantes hacen referencia principalmente a experiencias de atención a la diversidad inadecuadas vividas, por lo general, durante el Prácticum I. En este sentido, los participantes coinciden en subrayar la ausencia de ejemplos de buenas prácticas, así como la permanencia de una visión dicotómica arraigada en los centros escolares donde han realizado las prácticas externas, lo cuales continúan distinguiendo entre profesorado generalista y profesorado especialista. Esto último, de acuerdo con varios estudios (Echeita y Verdugo, 2004; Gallego y Rodríguez, 2012; Marchesi, 2001; Vigo, Soriano y Julve, 2010; Sevilla, Martín y Jenaro, 2017) tiene un impacto negativo sobre la confianza del profesorado generalista que no se siente lo suficientemente preparado para ofrecer una respuesta socioeducativa adecuada a las necesidades de todo su alumnado, en especial a aquellas del alumnado con NEE, como hemos podido corroborar a partir de los datos aportados por los participantes en cuanto a su formación. Esto conlleva, según Sapon y Chevin (2013) y González et al. (2016), que los futuros docentes relacionen fundamentalmente la atención a la diversidad con atender al alumnado con NEE, como hemos podido confirmar a lo largo de este estudio. Por consiguiente, los datos que se desprenden de este estudio ponen de relieve la necesidad de un replanteamiento y mejora del diseño del Prácticum en consonancia con las propuestas recogidas en varias investigaciones: una mejor planificación del período de prácticas externas por parte de la institución formadora en cuestión que no responda únicamente a oportunidades de inserción laboral de los futuros docentes o a cuestiones causales, sino a necesidades e intereses formativos (Sevilla, Martín y Jenaro, 2017); una alternancia mayor de los contenidos teóricos con el trabajo de campo a través de la reflexión guiada, la colaboración y la investigación-acción (Barbosa-Vioto y Vitaliano, 2013; Swain et al., 2012) y; una mayor oferta de experiencias que transformen los valores y creencias respecto a la enseñanza y el aprendizaje que estos traen a la universidad (Vélez et al., 2016; Vigo y Soriano, 2014).

c) Los datos relativos a las percepciones de las personas participantes acerca de su formación inicial a lo largo del módulo genérico revelan que la mayoría de ellas (24 de 38) no se consideran preparadas para atender a la diversidad, y en especial al alumnado con NEE. A este respecto, alegan que su formación tanto teórica como práctica ha sido insuficiente, en especial esta última. Entre los aspectos que consideran susceptibles de mejora señalan un aumento de los contenidos teóricos relacionados con la atención al alumnado con NEE, una presencia mayor de casos prácticos reales y otros contenidos prácticos preferentemente centrados en cómo llevar a cabo la comunicación con las familias y la realización de adaptaciones curriculares. Todo ello concuerda con los resultados procedentes de la investigación de Izuzquiza, Echeita y Simón (2015), concretamente, las debilidades percibidas en cuanto a la formación inicial recibida. Pese a las carencias destacadas respecto a su formación en materia de educación inclusiva, estimamos conveniente resaltar el testimonio de cuatro participantes quienes afirman que, a pesar de no sentirse lo suficientemente preparados, ni en la teoría ni en la práctica, consideran que su actitud ha mejorado en relación a la toma de conciencia de que es preciso atender socioeducativamente a todo el alumnado. Este dato coincide con lo arrojados por las investigaciones de Álvarez y Buenestado (2014) y Tárraga, Grau y Peirat (2013) que indican que, por lo general, las actitudes de los futuros docentes hacia la educación inclusiva son positivas. Profundizando en esto último, los resultados de 
nuestro estudio revelan que, aunque los participantes manifiesten una actitud positiva hacia la diversidad de su alumnado, la gran mayoría mantiene una percepción negativa sobre su formación, a lo que se une una escasez de formación práctica y de experiencias que, indudablemente, desde nuestro punto de vista, tendrán un impacto negativo sobre su futuras prácticas en las aulas, en línea con lo que sostienen varias investigaciones (Batsiou et al., 2008; Bravo, 2013; Izuzquiza, Echeita y Simón, 2015; Lindsay, 2010, Pegalajar y Colmenero, 2014; Sevilla, Martín y Jenaro, 2017).

d) Los datos que se desprenden de las percepciones de los participantes en cuanto a su aptitud y actitud para atender a la diversidad ponen de manifiesto que las principales aptitudes y actitudes referidas por los participantes son la empatía, compromiso, vocación, paciencia, confianza, actitud positiva, capacidad de adaptación, constancia, perseverancia y formación autodidacta y/o extracurricular. Todas ellas presumen una acción pedagógica de acuerdo con los principios que sustentan una educación inclusiva tal y como plantean Hopkins y Stem (1996) y Durán y Giné (2011). No obstante, cabe señalar que 10 participantes de 38 no han ofrecido información alguna sobre sus fortalezas pese a haber proporcionado datos en torno a sus debilidades, lo que nos invita a reflexionar sobre una posible falta de confianza y seguridad en sus aptitudes y actitudes para atender a la diversidad. Este pensamiento se confirma a partir de la información facilitada en cuanto a debilidades, concretamente los participantes concuerdan en que estas son la falta de formación práctica, la insuficiencia de experiencias previas y el miedo e inseguridad que les provoca no saber cómo atender a la diversidad de manera adecuada, coincidiendo igualmente con lo arrojado por la investigación de Izuzquiza, Echeita y Simón, (2015).

Tras haber puesto en discusión los resultados más relevantes de este estudio, podemos afirmar que una de las principales limitaciones del mismo es el tamaño de la muestra y el hecho de que haya sido concebido como un estudio exploratorio, por lo que la información recabada no siempre es lo suficientemente precisa, aunque, en términos generales, cumple con el objetivo de la investigación. En lo que respecta a las fortalezas, consideramos que los resultados de nuestro estudio validan y amplían la información de investigaciones previas a lo largo de las cuales se ha hecho uso fundamentalmente de instrumentos y estrategias de recogida de datos cuantitativas, por lo que se ofrece una perspectiva más profunda de las percepciones en cuanto a formación y experiencias en educación inclusiva de los futuros docentes. Paralelamente, los resultados de este estudio aportan información valiosa sobre cómo orientar la acción pedagógica de formadores de formadores en el ámbito de la educación inclusiva con el objetivo de suplir algunas carencias que albergan en la actualidad un gran número de planes de estudios (Vélez et al., 2016), al mismo tiempo que apunta a futuras líneas de investigación -y acción-, centradas sobre todo en el estudio curricular del Prácticum del Grado en Educación Primaria junto con un consecuente rediseño del mismo, así como una reconfiguración del plan de estudios de forma que este contenga un número mayor de contenidos teórico-prácticos, así como de objetivos y competencias en relación con la educación inclusiva a lo largo del módulo genérico.

Podemos concluir que este estudio nos ha permitido conocer en profundidad las experiencias y percepciones de docentes en formación inicial respecto a la formación recibida en materia de educación inclusiva durante los tres primeros cursos correspondientes al módulo genérico del Grado en Educación Primaria de la Facultad de Ciencias de la Educación de la Universidad de Granada. De modo que consideramos fundamental escuchar sus voces, dado que sus experiencias y percepciones pueden y deben servir de base para reorientar tanto el esquema de prácticas externas como el plan de estudios con el objetivo último de transformar nuestras escuelas en entornos escolares seguros y accesibles a todo el alumnado. 


\section{Referencias}

Álvarez, J.L. y Buenestado, M. (2015). Predictores de las actitudes hacia la inclusión de alumnado con necesidades educativas especiales en futuros profesionales de la educación. Revista Complutense de Educación, 26(3), 627-645.

Arnett, K. (2010). Scaffolding Inclusion in a Grade 8 Core French Classroom: An Exploratory Case Study, The Canadian Modern Language Review, $66,4,557-582$.

Azorín Abellán, C.M. (2017). Análisis de instrumentos sobre educación inclusiva y atención a la diversidad. Revista Complutense de Educación, 28 (4), 1043-1060.

Barbosa-Vioto, J., \& Vitaliano, C. (enero-junio, 2013). Educación inclusiva y formación docente: percepciones de estudiantes de pedagogía. Magis, 5(11), 353-373.

Batsiou, S.; Bebetsos, E.; Panteli, P. y Antoniou, P. (2008). Attitudes and intention of Greek and Cypriot primary education teachers towards teaching pupils with special educational needs in mainstream schools. International Journal of Inclusive Education, 12 (2), 201-219.

Bisquerra, R. (2019): Metodología de la Investigación Cualitativa. Madrid: La Muralla.

Boer, A.; Jan, S. y Minnaert, A. (2011). Regular primary school teachers' attitudes towards inclusive education: a review of the literature. International Journal of Inclusive Education, 15 (3), 331-353.

Brandes, J.A., Mcwhirter, P.T., Hary, K.A., Crowson, M.H. y Millsap, C.A. (2012). Development of the Indicators of Successful Inclusion Scale (ISIS): addressing ecological concerns. Teacher Development: An international journal of teachers' professional development, 14(4), 463-488.

Bravo, L. I. (2013). Percepción y opiniones hacia la educación inclusiva del profesorado y de las/os equipos directivos de los centros educativos de la Dirección Regional de Enseñanza en Cartago Costa Rica (Tesis doctoral).

Cardona, M.C. y Paz, C. (2012). Escala de Percepciones acerca de la Inclusión y la Atención a la Diversidad. Alicante: Universidad de Alicante.
Crisol, E. (2019). Hacia una educación inclusiva para todos. Nuevas contribuciones. Revista de currículum y formación del profesorado, 23, 1, 19.

Durán, David y Giné, Climent. (2011) La formación del profesorado para la educación inclusiva: Un proceso de desarrollo profesional y de mejora de los centros para atender la diversidad, Revista Latinoamericana de Educación inclusiva, 5(2), 153-170

Echeita, G. (2012). Competencias esenciales en la formación inicial de un profesorado inclusivo. Un proyecto de la Agencia Europea para el Desarrollo de las Necesidades Educativas Especiales. Tendencias Pedagógicas, 19, 7-24.

Gallego, J. L. y Rodríguez, A. (2012). ¿Cómo aprenden ahora los estudiantes de magisterio a atender a la diversidad de su alumnado? Revista de Currículum y Formación del Profesorado, 16 (2), 327-342.

Gónzalez-Gil, F., Martín-Pastor, E., Poy, R. \& Jenaro, C. (2016). Percepciones del profesorado sobre la inclusión: estudio preliminar. Revista Electrónica Interuniversitaria de Formación del Profesorado, 19(3), 11-24

Granada, M., Pomés, M. P., y Sanhueza, S. (2013). Actitud de los profesores hacia la inclusión educativa. Papeles de Trabajo, 25, 5159.

Hopkins, D.; Stern, D. (1996). Quality teachers, quality schools: International Perspectives and Pollicy Implications. Teaching and Teacher Education, 12, 5, 501-517.

Hunter-Johnson, Y., Newton, N., \& CambridgeJohnson, J. (2014). What does teachers' perception have to do with inclusive education: a Bahamian context. International Journal of Special Education, 29(1), 143-157.

Izuzquiza D, Echeita G, Simón C (2015) La percepción de estudiantes egresados de Magisterio en la Universidad autónoma de Madrid sobre competencia profesional para ser "profesorado inclusivo": un estudio preliminar. Tendencias Pedagógicas, 26, 197-216.

Karsenti, T. y Savoie-Zajc. (2017). La recherche en éducation. Étapes et approches. Canadá : Les Presses de l'Université de Montréal. 
León, M.J. (2011). La situación de la formación en educación inclusiva en los nuevos títulos de grado de magisterio en España. Revista Interuniversitaria de Formación del Profesorado, 70 (25), 145-163.

Ley Orgánica 8/2013, de 9 de diciembre, para la Mejora de la Calidad Educativa (LOMCE).

Lindsay, G. (2010). Intervención en el lenguaje en una escuela inclusiva. En V. M. Acosta \& A.M. Moreno (Eds.), Dificultades del lenguaje, colaboración e inclusión educativa (pp. 93-104). Barcelona: Lexus.

Marchesi, A. (2001): "La práctica de las escuelas inclusivas", en A. Marchesi, C. Coll y J. Palacios (Eds.), Desarrollo psicológico y educación. 3. Trastornos del desarrollo y necesidades educativas especiales. Madrid: Alianza.

Medina García, M. (2017): La educación inclusiva como mecanismo de garantía de la igualdad de oportunidades y no discriminación de las personas con discapacidad. Madrid: CERMI.

Palacios, A. y Romañach, J. (2008). El modelo de la diversidad: una nueva visión de la bioética desde la perspectiva de las personas con diversidad funcional (discapacidad), Revista Sociológica de Pensamiento Crítico, 2, 2, 37-47.

Pegalajar, M., \& Colmenero, M. (2014). Actitudes del docente de centros de educación especial hacia la inclusión educativa. Enseñanza \& Teaching, 32(2), 195- 213.

Polo, T., Fernández, C. y Díaz, C. (2011). Estudio de las actitudes de estudiantes de Ciencias Sociales y Psicología: relevancia de la información y contacto con personas discapacitadas. Universitas Psychologica, 10 (1), 113-123.

Sapon-Shevin, M. (2013). La inclusión real: Una perspectiva de justicia social. Revista de Investigación en Educación, 11, (3), 71-85.
Sevilla D, Martín M, Jenaro C (2017) Percepciones sobre la educación inclusiva: la visión de quienes se forman como docentes. Revista de Investigación Educativa, 25, 83-113.

Swain, K. D., Nordness. P. D. y Leader-Janssen, E. M. (2012). Changes in preservice teacher attitudes toward inclusion. Preventing School Failure, 56 (2), 75- 81.

Tárraga Mínguez, R., Grau Rubio, C., \& Peirat Chacón, J. (2013). Actitudes de los estudiantes del Grado de Magisterio y del Máster de Educación Especial hacia la inclusión educativa. Revista Electrónica Interuniversitaria De Formación Del Profesorado, 16(1), 55-72.

Tárraga, R., Grau, C. y Peirat, J. (2013). Actitudes de los estudiantes del Grado de Magisterio y del Máster de Educación Especial hacia la inclusión educativa. Revista Electrónica Interuniversitaria de Formación del Profesorado, $16(1)$.

Vélez Calvo, X., Tárraga Mínguez, R., Fernández Andrés, M.I. \& Sanz Cervera, P. (2016). Formación inicial de maestros en Educación Inclusiva: una comparación entre Ecuador y España. Revista Nacional e Internacional de Educación Inclusiva, 9(3), 75-94.

Verdugo, M.A. y Rodríguez, A. (2012). La inclusión educativa en España desde la perspectiva de alumnos con discapacidad intelectual, de familias y profesionales. Revista de Educación, 358, 450-470.

Vigo, B. y Soriano, J. (2014). Teaching practices and teachers' perceptions of group creative practices in inclusive rural schools. Ethnography and Education, 9 (3), 253-269.

Vigo, B., Soriano, J., \& Julve, C. (2010). Preparando profesores para la atención a la diversidad: potencialidades y limitaciones de un proyecto de innovación y mejora interdisciplinar. Revista Interuniversitaria de Formación del Profesorado, 24(3), 147-165. 
Anexos

Anexo I. Cuestionario utilizado.

\section{CUESTIONARIO SOBRE EXPERIENCIAS Y FORMACIÓN EN ATENCIÓN A LA DIVERSIDAD}

INSTRUCCIONES: el presente cuestionario es anónimo; disponéis de una hora y media para responder por escrito a las preguntas en el orden que prefiráis; intentad ejemplificar cada uno de vuestros argumentos de manera narrativa tratando de describir los sentimientos y/o emociones que os provocaron determinados acontecimientos; evitad hablar con vuestros compañeros y compañeras y utilizar el móvil durante su compleción.

Preguntas

1. ¿Quién es el alumnado con NEE (ACNEE)?

2. ¿Qué es para ti la atención a la diversidad?, ¿qué enfoques, metodologías, técnicas, estrategias, actividades...favorecen la atención a la diversidad en el área lingüística?

3. ¿De qué manera se atiende a la diversidad en las aulas de lengua castellana y literatura de los centros escolares andaluces? Describe alguna experiencia tomando como referencia el Prácticum de $3^{\circ}$ 잉

4. Describe alguna experiencia en la que hayas observado cómo algún docente atendía a la diversidad de manera adecuada en el aula de lengua castellana y literatura (puedes basarte en el Prácticum o en algún recuerdo)

5. Describe alguna experiencia en la que hayas observado cómo algún docente atendía a la diversidad de manera inadecuada en el aula de lengua castellana y literatura (puedes basarte en el Prácticum o en algún recuerdo)

6. ¿Consideras que tu formación hasta ahora te permite ofrecer una respuesta socioeducativa de calidad y equidad al alumnado ACNEE?, ¿echas en falta algo en tu formación? Describe tus fortalezas y debilidades como futuro docente para ofrecer una respuesta socioeducativa de calidad a las necesidades de este alumnado (formación, intereses, sentimientos, miedos, dudas...)

\section{Anexo II. Tabla I.}

\section{Relatos de experiencias de atención percibidas como inadecuadas durante el Prácticum I}

P3: "en las prácticas que realicé en tercero las adaptaciones que se daban a los alumnos con NEE se limitaban a un refuerzo fuera del aula, con lecturas adaptadas y libros de un nivel más bajo respecto a su edad. Dentro del aula se utilizaba libros "más fáciles", que no estaban adaptados y el uso de fichas de "refuerzo". Considero que el uso de materiales de un nivel menos no es una adaptación real ni ajustada a las necesidades y demandas de cada menor, considero que es una práctica inadecuada."

P4: "la atención a la diversidad se producía en un aula aparte, donde los niños salían durante esa hora con otro docente a un aula específica. Además, en el aula ordinaria el docente no atendía de manera adecuada a un alumno que no pronunciaba bien la "c". Cuando este alumno hablaba y pronunciaba mal dicha letra, éste se la repetía y si no la repetía bien le gritaba y lo sacaba a la pizarra para que pronunciase varias palabras con dicha letra". 
P5: "en el prácticum estuve en la clase de $2^{\circ}$ de primaria, la profesora únicamente se guiaba por el libro y por lo que éste exigía, sin embargo, no todos los alumnos presentaban las mismas necesidades, ya que una alumna no escribía ni leía correctamente y no hacía por pararse ni apoyarla. Lo mismo ocurría con un alumno con altas capacidades que se quedaba parado todo el tiempo".

P6: "en mi centro de prácticas no se atendía a la diversidad, puesto que un alumno que presentaba dificultades no fue atendido adecuadamente, ya que se le desatendía en el aula ordinaria mientras el resto seguían el ritmo normal de la clase. Mientras, el alumno con necesidades pasaba el tiempo realizando dibujos en el cuaderno y durante toda la jornada escolar permanecía en la silla sin atención ni adaptación. Además, no se le entregaron los materiales escolares hasta pasados tres meses del inicio del curso".

P8: "casi todas las experiencias que tuve en el prácticum fueron malas en este sentido. A mi parecer, los docentes no actuaban de forma correcta a la hora de atender a la diversidad. Una de mis experiencias fue ver cada día cómo a un alumno con NEE se le entregaba un material distinto al de los demás en clase de lengua castellana y se le aislaba del resto de la clase".

P9: "en el Prácticum observé cómo el docente discriminaba a un alumno no teniéndolo en cuenta ni proporcionándole ayuda y lo dejó de lado porque consideraba que el ritmo de clase se reducía bastante".

P12: "a un niño que tiene disgrafía, el profesor le obligaba a realizar las mismas actividades que a sus compañeros sin adaptación alguna y además después le regañaba por no hacerlo correctamente. El profesor no le daba pautas para facilitar su aprendizaje sino todo lo contrario".

P17: "en el prácticum había un alumno con Síndrome de Down y siempre que realizábamos alguna actividad, él no participaba o directamente lo ponían a realizar otra tarea como dibujar".

P19: "pocos y muy escasos ejemplos he visto de atención a la diversidad. Como mucho se les proporcionaba un cuadernillo especial "adaptado" solo para alumnado con NEE".

P20: "la maestra de inglés no era paciente con una alumna con dislexia y se enfadaba. La alumna se sentía avergonzada".

P22: "en mi prácticum no había atención a la diversidad, se daba el temario con normalidad sin tener en cuenta ninguna de las necesidades de los alumnos y el alumnado que le costaba más trabajo salía en determinadas horas al aula de apoyo".

P25: "durante el prácticum he visto profesorado que presionaba al alumnado con NEE y/o lo trataba de manera irrespetuosa".

P26: "en la mayoría de los casos no se les suele atender ni se les hacen adaptaciones curriculares. Lo más frecuente es que salgan del aula ordinaria y se les ayude en el aula de apoyo, pero siempre haciendo las mismas actividades que el resto de compañeros. La verdad es que no se les suele atender de manera adecuada, ya que no se les ayuda de manera individual, según sus necesidades".

P27: "en los centros que conozco no se lleva a cabo el proceso de la inclusión, es decir, a los alumnos que presentan alguna dificultad se les ha sacado de clase con el profesor/a de apoyo. Por ejemplo, en las prácticas de tercero había en el aula una alumna con déficit de audición y la sacaban prácticamente todo el día. A lo largo de mi vida todavía no he visto a ningún docente atendiendo adecuadamente a la diversidad. Sí que he los he visto interesándose por el alumno/a, intentando que sus capacidades mejoraran, pero no he visto una metodología inclusiva. He observado que algunos docentes a alumnado con NEE les han puesto en clase a hacer actividades distintas a las que están siguiendo el resto de compañeros sin ninguna supervisión del docente hacia ese alumnado".

P28: "los alumnos se dedicaban a leer solos sin la supervisión de ningún docente, apartados del resto de compañeros. Además, los docentes no se encargaban de corregir las actividades de refuerzo que les daban a los alumnos. No se les detectaba el problema que pudieran tener en esta área, por lo tanto, no se hacían adaptaciones curriculares, es decir, el alumno seguiría con las mismas carencias de aprendizaje al principio y final de curso".

P31: "en mi Prácticum no he visto apenas atención a la diversidad adecuada". 
P34: "desde mi experiencia, no se realizaba ninguna actividad que estuviera adaptada al alumno que presentaba discapacidad intelectual leve. La PT era la que lo atendía fuera del aula mayormente. Este mismo alumno presentaba dificultades visuales y en los exámenes había cosas que las hacía mal porque nos las veía bien. Fui yo la que le propuso a la tutora que se le aumentara el tamaño de la letra para él. Los exámenes estaban sacados del libro que viene junto al libro del profesor y era el mismo para todos sin atender a las distintas necesidades. Los NEE trabajaban principalmente fuera del aula".

P35: "en el prácticum no dejaban leer en clase a los alumnos que peor iban o tardaban más. También sacaban del aula a los alumnos que peor llevaban la lectura con una profesora de apoyo. Tampoco daban distintas tareas a alumnado que presentaba distinto ritmo".

P36: "mi experiencia es que no se atiende a la diversidad. Es más fácil enviar al alumno al aula de apoyo antes que incluirlo en el aula ordinaria".

P37: "no siempre se realizaba una atención a la diversidad adecuada en mi centro de prácticas. Conocí dos casos de alumnado con NEE en diferentes cursos, uno en $6^{\circ}$ de primaria y una niña de $2^{\circ}$ de primaria con tutores diferentes. El chico de $6^{\circ}$ era ignorado durante toda la clase, se limitaban a "dejarlo aprender" en el aula de apoyo, mientras que en el caso de la chica de $2^{\circ}$ de primaria sí la tenían en cuenta y la ayudaban, pero desde mi punto de vista faltaba implicación por parte de los tutores".

P38: "teniendo en cuenta mi experiencia, no se está atendiendo a la diversidad correctamente porque tratan al alumnado por igual. Cada persona es diferente. En mi caso, se trabajaba con el libro de texto y de ahí poco se salía. Normalmente al alumnado con NEE lo sacan del aula y suelen trabajar con el profesorado de PT y AL. Un día, mi tutora de prácticas le pidió que leyese a un niño con Asperger en voz alta y el niño no quiso leer. La profesora, cabreada, le volvió a pedir que leyese y este lo hizo, pero imitando a un bebé. Otro caso que presencié fue un niño con dificultades en lectoescritura. Le pregunté a mi tutora si este niño tenía alguna adaptación, a lo que ella respondió que no".

Tabla I. Relatos de las experiencias inadecuadas de atención a la diversidad. Fuente: elaboración propia 